\title{
INBREEDING AS A RESULT OF IMPRINTING
}

\author{
P. O'DONALD
}

Department of Genetics, University of Cambridge

Received I $9 \cdot x$ ii. 59

\section{INTRODUCTION}

THE phenomenon of imprinting is now well known in many birds, in fish, and apparently in some insects (Thorpe, 1956). In geese, which show the most extreme form of this behaviour, a man or large moving object first seen by the newly-hatched gosling will be accepted by the bird as its parent, and later on, as a member of its species to which the sexual behaviour will be attached. Recently Huxley (1955) has suggested that the imprinting of the young by their mothers may account for the assortive mating between the Blue and Lesser Snow Goose, both apparently phases of Anser cerulescens. Assortive mating also appears likely (O'Donald, r959a) among the phases-pale, intermediate and dark-of the Arctic Skua, Sterc rarius parasiticus. It may therefore be of some interest to examine the rate of inbreeding which such a system might produce. More generally, it would seem possible that a slight tendency to marry a partner similar in certain respects to the parent of the opposite sex may be present even in man. We shall first of all, therefore, discuss the case where imprinting is complete; and secondly the situation in which only a proportion of the population imprints, the remainder mating at random.

\section{THE GENERATION MATRIX}

We shall assume that both homozygotes and heterozygote are recognizable in a population in which two alleles are segregating. There are four different types of mating :-

(I) The offspring of matings of like homozygotes only reproduce similar mating types.

(2) For matings homozygote $\times$ heterozygote, however, equal numbers of homozygous and heterozygous offspring will be produced. Of the homozygous offspring, assuming mating is equally likely with either of the two parental genotypes, homozygote $\times$ homozygote and heterozygote $\times$ homozygote matings should occur with equal frequency. Similarly, the heterozygous offspring should give equal numbers of heterozygote $\times$ homozygote and heterozygote $\times$ heterozygote matings. Thus a mating $\mathrm{AA} \times \mathrm{AB}$ is expected to yield in the next generation $\frac{1}{4} \mathrm{AA} \times \mathrm{AA}, \frac{1}{2} \mathrm{AA} \times \mathrm{AB}$ and $\frac{1}{4} \mathrm{AB} \times \mathrm{AB}$.

(3) Heterozygote $\times$ heterozygote matings produce offspring all of 
which will mate with the heterozygote: the mating type $\mathrm{AB} \times \mathrm{AB}$ gives $\frac{1}{4} \mathrm{AA} \times \mathrm{AB}, \frac{1}{2} \mathrm{AB} \times \mathrm{AB}$ and $\frac{1}{4} \mathrm{BB} \times \mathrm{AB}$.

(4) Finally, matings of unlike homozygotes, producing all heterozygous offspring, yield equal numbers of the two homozygote $\times$ heterozygote mating types.

Thus the following generation matrix may be built up :-

\begin{tabular}{cccccccc}
\multicolumn{2}{c}{} & \multicolumn{7}{c}{ Frequency } \\
$\mathrm{AA} \times \mathrm{AA}$ & $\mathrm{P}_{n+1}$ & $\mathrm{I}$ & $\cdot$ & $\frac{1}{4}$ & $\cdot$ & $\cdot$ & $\cdot$ \\
$\mathrm{BB} \times \mathrm{BB}$ & $\mathrm{Q}_{n+1}$ & $\cdot$ & $\mathrm{I}$ & $\cdot$ & $\frac{1}{4}$ & $\cdot$ &. \\
$\mathrm{AA} \times \mathrm{AB}$ & $\mathrm{R}_{n+1}$ & $\cdot$ & $\cdot$ & $\frac{1}{2}$ & $\cdot$ & $\frac{1}{4}$ & $\frac{1}{2}$ \\
$\mathrm{BB} \times \mathrm{AB}$ & $\mathrm{S}_{n+1}$ & $\cdot$ & $\cdot$ & $\cdot$ & $\frac{1}{2}$ & $\frac{1}{4}$ & $\frac{1}{2}$ \\
$\mathrm{AB} \times \mathrm{AB}$ & $\mathrm{T}_{n+1}$ & $\cdot$ & $\cdot$ & $\frac{1}{4}$ & $\frac{1}{4}$ & $\frac{1}{2}$ & $\cdot$ \\
$\mathrm{AA} \times \mathrm{BB}$ & $\mathrm{U}_{n+1}$ & $\cdot$ &. & $\cdot$ & $\cdot$ & $\cdot$ &.
\end{tabular}

This matrix has the latent roots I (repeated), $\frac{1}{2},(2+\sqrt{2}) / 4,(2-\sqrt{2}) / 4$ and $o$. Here the dominant latent root is $(2+\sqrt{2}) / 4$. To find the principal component of frequency corresponding with this root, the columns of the matrix (using the notation of Fisher, 1949) are read as homogeneous linear functions of the coefficients $a \ldots e$. Thus for the latent root $\lambda=(2+\sqrt{2}) / 4$, we have the equations,

so that

$$
\begin{aligned}
-\frac{1}{4} \sqrt{2} \cdot c+\frac{1}{4} \cdot e & =0 \\
-\frac{1}{4} \sqrt{2} \cdot d+\frac{1}{4} \cdot e & =0 \\
\frac{1}{4} \cdot c+\frac{1}{4} \cdot d-\frac{1}{4} \sqrt{2} \cdot e & =0,
\end{aligned}
$$

$$
c=d=e / \sqrt{2} \text {. }
$$

Hence the principal component is

$$
\mathrm{D}=\mathrm{R}+\mathrm{S}+\mathrm{T} \cdot \sqrt{2} .
$$

Similarly, the principal components of frequency may be built up for the remaining latent roots. We thus have :-

$$
\begin{array}{ll}
\text { Principal component } & \text { Latent Root } \\
\mathrm{A}=4 \mathrm{P}+3 \mathrm{R}+\mathrm{S}+2 \mathrm{~T} & \mathrm{I} \\
\mathrm{B}=4 \mathrm{Q}+\mathrm{R}+{ }_{3} \mathrm{~S}+2 \mathrm{~T} & \mathrm{I} \\
\mathrm{C}=\mathrm{R}-\mathrm{S} & \frac{1}{2} \\
\mathrm{D}=\mathrm{R}+\mathrm{S}+\sqrt{2} \cdot \mathrm{T} & (2+\sqrt{2}) / 4 \\
\mathrm{E}=\mathrm{R}+\mathrm{S}-\sqrt{2} \cdot \mathrm{T} & (2-\sqrt{2)} / 4 \\
\mathrm{F}=\mathrm{U} & 0
\end{array}
$$

\section{THE RELATIVE FREQUENCIES AND COMPLEXITIES}

If the principal components $\mathrm{C}$ and $\mathrm{E}$ are put equal to zero (that is to assume that sufficient generations have passed to ensure that only the principal component corresponding with the dominant latent 
root is of importance), we have

Hence

$$
\begin{aligned}
\mathrm{R} & =\mathrm{S} \\
\mathrm{R}+\mathrm{S} & =\sqrt{2} \cdot \mathrm{T}
\end{aligned}
$$

$$
\begin{aligned}
\mathrm{R}+\mathrm{S}+\mathrm{T} & =\quad(\mathrm{I}+\sqrt{2}) \mathrm{T} \\
& =\sqrt{2}(\mathrm{I}+\sqrt{2}) \mathrm{S} \\
& =\sqrt{2}(\mathrm{I}+\sqrt{2}) \mathrm{R}
\end{aligned}
$$

Thus the relative frequencies of the heterogeneous matings are :-

$\begin{array}{ccc}\text { Mating } & \text { Symbol } & \text { Relative freque } \\ \mathrm{AA} \times \mathrm{AB} & \mathrm{R} & \mathrm{I} /(2+\sqrt{2}) \\ \mathrm{BB} \times \mathrm{AB} & \mathrm{S} & \mathrm{I} /(2+\sqrt{2}) \\ \mathrm{AB} \times \mathrm{AB} & \mathrm{T} & \mathrm{I} /(\mathrm{I}+\sqrt{2})\end{array}$

Inserting the relative frequencies of $\mathrm{R}, \mathrm{S}$ and $\mathrm{T}$ in the principal component $\mathrm{D}$, we find

$$
\mathrm{D}=4 /(2+\sqrt{2}) .
$$

Hence in standard measure,

$$
{ }_{4} \mathrm{D}=(2+\sqrt{2}) \mathrm{R}+(2+\sqrt{2}) \mathrm{S}+(2+2 \sqrt{2}) \mathrm{T} .
$$

The coefficients of $\mathrm{R}, \mathrm{S}$ and $\mathrm{T}$ form the complexities of the heterogeneous mating types.

$\begin{array}{cccc}\text { Mating type } & \text { Symbol } & & \begin{array}{c}\text { Complexity } \\ \text { in standard measure }\end{array} \\ \mathrm{AA} \times \mathrm{AB} & \mathrm{R} & 2+\sqrt{2} & 0.853553 \\ \mathrm{BB} \times \mathrm{AB} & \mathrm{S} & 2+\sqrt{2} & 0.853553 \\ \mathrm{AB} \times \mathrm{AB} & \mathrm{T} & 2+2 \sqrt{2} & 1.207107 \\ & & \div 4 & \end{array}$

The complexities measure the value for each mating type which multiplied by $\{(2+\sqrt{2}) / 4\}^{n}$ gives the probability of this mating type still being present $n$ generations later.

\section{THE RATE OF INBREEDING}

\begin{tabular}{|c|c|c|c|}
\hline & Selfing & Sibbing & Imprinting \\
\hline$\lambda$ & 0.5 & 0.809017 & 0.853553 \\
\hline$-\log _{e} \lambda$ & 0.69315 & $0 \cdot 21194$ & $0 \cdot 15^{8} 35$ \\
\hline $\mathrm{I} /\left(-\log _{e} \lambda\right)$ & $1 \cdot 443$ & $4 \cdot 718$ & $6 \cdot 315$ \\
\hline
\end{tabular}

The rate of progress towards matings involving only like homozygotes depends essentially on the dominant latent root. Fisher's method of comparing different systems of inbreeding is to use $\left(-\log _{e} \lambda\right)$ : then the number of generations required to make a fixed amount of progress is measured by $\mathrm{I} /\left(-\log _{e} \lambda\right)$. Thus for selfing, sibbing and imprinting, we have :- 


\section{INCOMPLETE IMPRINTING}

The case now to be considered is that in which a proportion $\alpha$ of the population imprints, while the remainder mate at random. Using the same symbols as before for the different matings, we have the following set of recurrence relations.

$$
\begin{aligned}
\mathrm{P}^{\prime} & =\alpha\left(\mathrm{P}+\frac{1}{4} \mathrm{R}\right)+(\mathrm{I}-\alpha)\left(\mathrm{P}+\frac{1}{2} \mathrm{R}+\frac{1}{4} \mathrm{~T}\right)^{2} \\
\mathrm{Q}^{\prime} & =\alpha\left(\mathrm{Q}+\frac{1}{4} \mathrm{~S}\right)+(\mathrm{I}-\alpha)\left(\mathrm{Q}+\frac{1}{2} \mathrm{~S}+\frac{1}{4} \mathrm{~T}\right)^{2} \\
\mathrm{R}^{\prime} & =\alpha\left(\frac{1}{2} \mathrm{R}+\frac{1}{4} \mathrm{~T}+\frac{1}{2} \mathrm{U}\right)+2(\mathrm{I}-\alpha)\left(\mathrm{P}+\frac{1}{2} \mathrm{R}+\frac{1}{4} \mathrm{~T}\right)\left(\frac{1}{2} \mathrm{R}+\frac{1}{2} \mathrm{~S}+\frac{1}{2} \mathrm{~T}+\mathrm{U}\right) \\
\mathrm{S}^{\prime} & =\alpha\left(\frac{1}{2} \mathrm{~S}+\frac{1}{4} \mathrm{~T}+\frac{1}{2} \mathrm{U}\right)+2(\mathrm{I}-\alpha)\left(\mathrm{Q}+\frac{1}{2} \mathrm{~S}+\frac{1}{4} \mathrm{~T}\right)\left(\frac{1}{2} \mathrm{R}+\frac{1}{2} \mathrm{~S}+\frac{1}{2} \mathrm{~T}+\mathrm{U}\right) \\
\mathrm{T}^{\prime} & =\alpha\left(\frac{1}{4} \mathrm{R}+\frac{1}{4} \mathrm{~S}+\frac{1}{2} \mathrm{~T}\right)+(\mathrm{I}-\alpha)\left(\frac{1}{2} \mathrm{R}+\frac{1}{2} \mathrm{~S}+\frac{1}{2} \mathrm{~T}+\mathrm{U}\right)^{2} \\
\mathrm{U}^{\prime} & =2(\mathrm{I}-\alpha)\left(\mathrm{P}+\frac{1}{2} \mathrm{R}+\frac{1}{4} \mathrm{~T}\right)\left(\mathrm{Q}+\frac{1}{2} \mathrm{~S}+\frac{1}{4} \mathrm{~T}\right),
\end{aligned}
$$

where $\mathrm{P}=\mathrm{P}_{n}, \mathrm{P}^{\prime}=\mathrm{P}_{n+1}$, etc.

Then we have, putting $\mathrm{P}+\mathrm{Q}=\mathrm{I}-(\mathrm{R}+\mathrm{S}+\mathrm{T}+\mathrm{U}), \frac{1}{2} \mathrm{R}^{\prime}+\frac{1}{2} \mathrm{~S}^{\prime}+\mathrm{T}^{\prime}$ $=\left(\mathrm{I}-\frac{1}{2} \alpha\right)\left(\frac{1}{2} \mathrm{R}+\frac{1}{2} \mathrm{~S}+\frac{1}{2} \mathrm{~T}+\mathrm{U}\right)+\frac{1}{2} \alpha\left(\frac{1}{2} \mathrm{R}+\frac{1}{2} \mathrm{~S}+\mathrm{T}\right)$. But $\frac{1}{2} \mathrm{R}+\frac{1}{2} \mathrm{~S}+\mathrm{T}$ is the frequency of heterozygotes: letting this value be $v$, we obtain

$$
\begin{aligned}
v^{\prime} & =\frac{1}{2} \alpha v+\left(\mathrm{I}-\frac{1}{2} \alpha\right) \cdot\left(\frac{1}{2} \mathrm{R}+\frac{1}{2} \mathrm{~S}+\frac{1}{2} \mathrm{~T}+\mathrm{U}\right) \\
& =v+\left(\mathrm{I}-\frac{1}{2} \alpha\right)\left(\mathrm{U}-\frac{1}{2} \mathrm{~T}\right) .
\end{aligned}
$$

Hence at equilibrium, when $v^{\prime}=v$, we have $\mathrm{U}=\frac{1}{2} \mathrm{~T}$. Putting $\mathrm{U}^{\prime}=\frac{1}{2} \mathrm{~T}^{\prime}$ and $\mathrm{U}=\frac{1}{2} \mathrm{~T}$, we obtain

$$
\begin{aligned}
& \frac{1}{2} \alpha\left(\frac{1}{2} \mathrm{R}+\frac{1}{2} \mathrm{~S}+\mathrm{T}\right)+(\mathrm{I}-\alpha)\left(\frac{1}{2} \mathrm{R}+\frac{1}{2} \mathrm{~S}+\mathrm{T}\right)^{2} \\
= & 4(\mathrm{I}-\alpha)\left(\mathrm{P}+\frac{1}{2} \mathrm{R}+\frac{1}{2} \mathrm{U}\right)\left(\mathrm{Q}+\frac{1}{2} \mathrm{~S}+\frac{1}{2} \mathrm{U}\right),
\end{aligned}
$$

or

$$
\frac{1}{2} \alpha v+(\mathrm{I}-\alpha) v^{2}=4(\mathrm{I}-\alpha) u w,
$$

where $u$ and $w$ are the frequencies of the two homozygotes. Then we have

or

$$
\alpha v / 2(I-\alpha)=4 u w-v^{2},
$$

$$
\alpha(\mathrm{I}-\mathrm{F}) / 4(\mathrm{I}-\alpha)=\mathrm{F},
$$

where $\mathrm{F}=\mathrm{I}-v / 2 p q=\left(4 u w-v^{2}\right) / 4 p q$ is the inbreeding coefficient and $p$ and $q$ are the gene frequencies. Hence at equilibrium the population consists of

$$
\left(p^{2}+\mathrm{F} p q\right) \mathrm{AA}+2 p q(\mathrm{I}-\mathrm{F}) \mathrm{AB}+\left(q^{2}+\mathrm{F} p q\right) \mathrm{BB},
$$

where $\mathrm{F}=\alpha /\left(4-3^{\alpha}\right)$. Thus when $p$ and $q$ are equal, an equilibrium is established at

$$
v_{e}=2(1-\alpha) /(4-3 \alpha)
$$

\section{RATE OF APPROACH TO EQUILIBRIUM}

To obtain the rate of approach to equilibrium it is necessary to find a recurrence relation in $v$ only. This is made simpler if we put $P=Q$ and $R=S$, which is equivalent to assuming equality of gene 
frequency. By this device, the recurrence relations can be re-written in terms involving only $\mathrm{R}, \mathrm{T}$ and $\mathrm{U}$ :

$$
\begin{aligned}
\mathrm{R}^{\prime} & =\frac{1}{2} \alpha\left(\mathrm{R}+\frac{1}{2} \mathrm{~T}+\mathrm{U}\right)+(\mathrm{I}-a)\left(\mathrm{R}+\frac{1}{2} \mathrm{~T}+\mathrm{U}\right)\left\{\mathrm{I}-\left(\mathrm{R}+\frac{1}{2} \mathrm{~T}+\mathrm{U}\right)\right\} \\
\mathrm{T}^{\prime} & =\frac{1}{2} \alpha(\mathrm{R}+\mathrm{T})+(\mathrm{I}-a)\left(\mathrm{R}+\frac{1}{2} \mathrm{~T}+\mathrm{U}\right)^{2} \\
\mathrm{U}^{\prime} & =\frac{1}{2}(\mathrm{I}-\alpha)\left\{\mathrm{I}-\left(\mathrm{R}+\frac{1}{2} \mathrm{~T}+\mathrm{U}\right)\right\}^{2} .
\end{aligned}
$$

Then we have, in generation $(n+2)$

$$
v^{\prime \prime}=\frac{1}{2} a v^{\prime}+\left(\mathrm{I}-\frac{1}{2} a\right)\left(\mathrm{R}^{\prime}+\frac{1}{2} \mathrm{~T}^{\prime}+\mathrm{U}^{\prime}\right) .
$$

But

and

$$
\mathrm{R}^{\prime}+\frac{1}{2} \mathrm{~T}^{\prime}+\mathrm{U}^{\prime}=\frac{1}{4} \alpha \nu+\frac{1}{2} \alpha\left(\mathrm{R}+\frac{1}{2} \mathrm{~T}+\mathrm{U}\right)+\frac{1}{2}(\mathrm{I}-\alpha)
$$

$$
\mathrm{R}+\frac{1}{2} \mathrm{~T}+\mathrm{U}=\left(v^{\prime}-\frac{1}{2} \alpha v\right) /\left(\mathrm{I}-\frac{1}{2} \alpha\right) .
$$

Thus the recurrence relation required is

$$
v^{\prime \prime}=\alpha v^{\prime}+\frac{1}{8} \alpha(2-3 \alpha) v+\frac{1}{2}(\mathrm{r}-\alpha)\left(\mathrm{r}-\frac{1}{2} \alpha\right) .
$$

It may be noted that $v_{e}$ satisfies this equation.

Putting $v=\{2(1-a) /(4-3 a)+x\}$ gives a recurrence equation in $x$ which does not involve a constant term, namely

$$
x^{\prime \prime}=\alpha x^{\prime}+\alpha x\left(2-3^{\alpha}\right) / 8 .
$$

Thus the rate of approach to equilibrium will be determined by the roots of the equation

$$
y^{2}-\alpha y-\alpha\left(2-3^{\alpha}\right) / 8=0 .
$$

\begin{tabular}{|c|c|c|c|c|}
\hline$a$ & $v_{e}$ & $\lambda$ & $-\log _{e} \lambda$ & $\mathrm{I} /\left(-\log _{e} \lambda\right)$ \\
\hline $0.0 \mathrm{I}$ & 0.49874 & $0 \cdot 0548748$ & $2 \cdot 9027$ & 0.3445 \\
\hline $0 \cdot I$ & 0.48649 & 0.204 II & $\mathrm{I} \cdot 58 \mathrm{gI}$ & 0.6293 \\
\hline 0.2 & 0.47059 & 0.312132 & $I \cdot I 643$ & 0.8589 \\
\hline $0 \cdot 3$ & $0.45 \mathrm{I} 6 \mathrm{I}$ & 0.402488 & 0.91009 & I $\cdot 099$ \\
\hline $0 \cdot 4$ & 0.42857 & 0.482843 & 0.72806 & $\mathrm{I} \cdot 374$ \\
\hline 0.5 & 0.40000 & 0.556 I 86 & 0.58665 & $1 \cdot 705$ \\
\hline 0.6 & $0 \cdot 36364$ & 0.624037 & 0.47155 & $2 \cdot 12$ I \\
\hline 0.7 & $\begin{array}{r}30304 \\
0.31579\end{array}$ & $0.68354^{2}$ & 0.38047 & $2 \cdot 628$ \\
\hline 0.8 & 0.25000 & 0.7464 Io & $0.2924^{8}$ & $3 \cdot 419$ \\
\hline $0 \cdot 9$ & $0.153^{8} 5$ & $0.80178 \mathrm{I}$ & 0.22092 & $4 \cdot 527$ \\
\hline 0.99 & 0.019417 & $0.84853^{6}$ & O.I 6424 & $6 \cdot 089$ \\
\hline
\end{tabular}

The roots are

$$
\frac{1}{2} \alpha \pm \frac{1}{2} \sqrt{\alpha\left(\mathrm{I}-\frac{1}{2} \alpha\right)}
$$

of which the dominant root is of course the one with the positive sign. It may be noted that if $\alpha=\mathrm{I}$, we have the case of complete imprinting and the dominant root is $\frac{1}{2}+\frac{1}{2} \sqrt{\frac{1}{2}}$ or $(2+\sqrt{2}) / 4$ as was obtained from the matrix.

Some numerical results of this solution are shown in table $\mathrm{I}$.

TABLE I

Thus for small values of $a$ the equilibrium point is very close to that for random mating and equilibrium is rapidly attained. 


\section{ASSORTIVE MATING IN THE ARCTIC SKUA}

The genetics of the colour phases of the Arctic Skua are not, apparently, as simple as would permit a direct application of the calculations put forward here. The situation is complicated by the semi-dominance of the dark allele, by classification difficulties, and by the likelihood of some form of disturbance, possibly viability, in the data (O’Donald, I959b).

TABLE 2

\begin{tabular}{|c|c|c|c|c|}
\hline Locality and year & $\mathbf{P} \times \mathbf{P}$ & $P \times D$ & $\mathrm{D} \times \mathrm{D}$ & $\chi^{2}$ \\
\hline $\begin{array}{l}\text { Fair Isle, I954-58. } \\
\text { Foula, I } 948 . \\
\text { Unst, I } 948 . \\
\text { Yell and Fetlar, } \\
\text { Noss, I } 94^{8} 6 . \\
\text { Caithness, I953 } \\
\text { Unst, I959. }\end{array}$ & $\begin{array}{r}10 \\
2 \\
4 \\
5 \\
7 \\
1 \\
9\end{array}$ & $\begin{array}{r}34 \\
7 \\
\text { I } 5 \\
25 \\
9 \\
\text { I I } \\
\text { I } 9\end{array}$ & $\begin{array}{r}64 \\
9 \\
3^{6} \\
36 \\
21 \\
9 \\
43\end{array}$ & $\begin{array}{l}I \cdot 99177 \\
0 \cdot 02880 \\
0 \cdot 7978 \text { I } \\
0 \cdot 00784 \\
5 \cdot 04175 \\
0.27320 \\
5 \cdot 13699\end{array}$ \\
\hline Total & $3^{8}$ & 120 & 218 & $10 \cdot 23997$ \\
\hline
\end{tabular}

The possibility of assortive mating among the phases has already been discussed. Additional data have now been collected from Unst, Shetland, lending support to this conclusion. The whole of the data now available are given in table 2 , where $2 \times 2$ contingency tests of independence have been used to give $\chi^{2}$ for one degree of freedom with Yates' correction. " $\mathrm{D}$ " represents dark and " $\mathrm{P}$ " pale.

TABLE 3

\begin{tabular}{|c|c|c|c|c|}
\hline & & \multicolumn{2}{|c|}{ Chicks } & \multirow{2}{*}{ Total } \\
\hline & & Like & Unlike & \\
\hline \multirow{3}{*}{ Parents } & \multirow{3}{*}{$\begin{array}{l}\text { Like } \\
\text { Unlike }\end{array}$} & I 2 & 6 & I 8 \\
\hline & & 5 & 5 & IO \\
\hline & & 17 & I I & 28 \\
\hline
\end{tabular}

By summing the separate values of $\chi^{2}$ for each locality, we obtain $\chi^{2}{ }_{\text {total }}$ for seven degrees of freedom. Subtracting the $\chi^{2}$ value for the total data, we find $\chi^{2}$ heterogeneity for six degrees of freedom. Thus $\chi_{\text {total }}^{2}=\mathrm{I} 3.2782$ and $\chi^{2}$ het. $=3.0382$.

The evidence thus appears fairly strongly in favour of assortive mating, and there is no evidence of heterogeneity.

At Fair Isle, however, data have also been collected involving birds of the next generation. This has been made possible by an extensive ringing programme begun in 1948 by $\mathrm{K}$. Williamson, the 
first warden of the bird observatory, and continued from 1957 by the present warden, Peter Davis, and myself. Owing to the great increase in the Arctic Skua colony through these years, it has been possible to recapture a number of breeding birds that were ringed as chicks. These data have been arranged in a $2 \times 2$ contingency table (table 3 ) according to whether the mating of the offspring is like-phased or unlike-phased in relation to a similar classification of the parental mating.

Fisher's exact test (Fisher, I954) for the probability of this and more extreme sets of values gives a one-tailed probability of 0.3205 . These data thus provide no evidence for imprinting; but in view of the only slight tendency to assortive mating in the population as a whole, a large body of data would presumably be needed to establish whether this depended upon imprinting.

\section{SUMMARY}

The rate of inbreeding as a result of the imprinting of young by their parents is considered, firstly in the case of complete imprinting, and secondly where only a proportion of the population imprints. Complete imprinting leads to homozygosity with an equivalent generation time of $6 \cdot 315$ as against $4 \cdot 7$ r 8 for sib-mating and $1 \cdot 443$ for selfing. Thus complete imprinting takes $1 \cdot 33^{8}$ times as long as sibmating and 4.377 times as long as selfing to achieve the same degree of homozygosity.

In the more realistic case where only a proportion of the population imprints, an equilibrium is established and a polymorphism will result. Where the proportion of imprinting individuals is small, however, the equilibrium point is very close to that for random mating and equilibrium is rapidly attained.

Assortive mating in the Arctic Skua is discussed, but more data are required to establish whether imprinting is a significant factor affecting it.

Acknowledgments. - I wish to thank Mr P. E. Davies, whom it has been my privilege to assist in the work on the Arctic Skua at Fair Isle, for making the records at the bird observatory available to me. This work was done during the tenure of a Nature Conservancy Research Studentship.

\section{REFERENCES}

FISHER, R. A. I949. The Theory of Inbreeding. Oliver and Boyd, Edinburgh. FISHER, R. A. I954. Statistical Methods for Research Workers. Oliver and Boyd, Edinburgh.

HuXley, J. s. 1955. Morphism in birds. Acta XI Congr. Int. Orn., Basel, 309-328. o'donald, P. I959a. Possibility of assortive mating in the Arctic Skua. Nature, I $83, \mathrm{I} 2 \mathrm{IO}-\mathrm{I} 2 \mathrm{II}$.

o'donald, P. I959b. The Genetics of the colour phases of the Arctic Skua. Heredity, I3, 48I-486.

THORPE, w. H. 1956. Learning and Instinct in Animals. Methuen, London. 